\title{
A prática da violência contra idosos e fatores associados a essa conduta
}

\author{
The practice of violence against the elderly and factors associated with this conduct
}

\section{La práctica de la violencia contra los ancianos y los factores asociados con esta conducta}

João Nivaldo Sampaio Novaes Júnior ${ }^{1 *}$, Letícia Rezende de Morais ${ }^{1}$, Gabriel Antônio Simões Costa $^{1}$, Iara Pinheiro Calili ${ }^{1}$, Larissa Shirley Gomes Lima ${ }^{1}$, Ana Carolina Mohr ${ }^{1}$, Henrique Reis Rabelo Costa', Emanuela Pontes Pereira Silveira ${ }^{1}$, Gilberto Antônio Reis'.

\section{RESUMO}

Objetivo: Identificar os fatores de risco relacionados à violência contra o idoso de modo a nortear estratégias voltadas para o cuidado integral à pessoa idosa e para a prevenção desse agravo. Métodos: Trata-se de uma revisão sistemática, com busca dos estudos nas bases de dados Scientific Electronic Library Online (Scielo) e Portal de Periódicos CAPES. Para a pesquisa, utilizou-se os seguintes descritores: "idoso" e "violência". Foram incluídas publicações dos últimos 5 anos em inglês, português e espanhol, bem como estudos quantitativos e qualitativos. Resultados: Foram identificados 295 artigos em que contemplamos 19 para a confecção do trabalho. Todas foram publicações nacionais, sendo 17 delas em português, com uma prevalência maior dentre os periódicos, a Revista Brasileira de Enfermagem e a Revista Brasileira de Geriatria e Gerontologia e, como delineamento de estudo, as entrevistas semiestruturadas tiveram um maior número de publicações. Considerações finais: $O$ gênero feminino, o grau de dependência funcional e a relação de proximidade com agressor representam importantes atributos associados às vítimas de abusos. Indivíduos do sexo masculino, solteiros e membro da própria família caracterizam o perfil do agressor. Informações sobre fatores de risco associados à violência contra o idoso auxiliam na delimitação do problema e em seu enfrentamento.

Palavras-chave: Idoso, Fatores de risco, Violência.

\section{ABSTRACT}

Objective: To identify risk factors related to violence against the elderly in order to guide strategies to provide comprehensive care for the elderly and preventing abuse. Methods: A systematic review, searching for studies in the Scientific Electronic Library Online (SciELO) and CAPES Journal Portal databases was conducted. For the research step, the following descriptors were used: "elderly" and "violence". Publications of the last 5 years in English, Portuguese and Spanish were included, as well as quantitative and qualitative studies. Results: A total of 295 articles were identified, including 19 selected for this review. All of them consisted of national publications, 17 of which were in Portuguese, with its higher prevalence published on Revista Brasileira de Enfermagem and Revista Brasileira de Geriatria e Gerontologia journals, and, as a study design, semi-structured interviews had a higher number of publications. Final considerations: Female gender, functional dependence degree and close relationship with the aggressor represent important attributes associated with victims of abuse. Male gender, single and family member characterize the aggressor profile. Providing information on risk factors related to violence against the elderly helps to define the problem and to deal with it.

Keywords: Aged, Risk factors, Violence.

\section{RESUMEN}

Objetivo: Identificar factores de riesgo relacionados con la violencia contra las personas mayores para orientar estrategias dirigidas a la atención integral de personas mayores y la prevención de este agravio. Métodos: Esta es una revisión sistemática, con una búsqueda de estudios en la base de datos de la Biblioteca Electrónica Científica en línea (SciELO) y en el portal CAPES Journal. Para la investigación, se utilizaron los siguientes descriptores: "ancianos" y "violencia". Se incluyeron publicaciones de los últimos 5 años en inglés, portugués y español, así como estudios cuantitativos y cualitativos. Resultado: Se identificaron 295 artículos, incluidos 19 para el trabajo. Todas eran publicaciones nacionales, 17 de las cuales estaban en portugués, con una mayor prevalencia entre las revistas: Revista Brasileira de Enfermagem, Revista Brasileira de Geriatria e Gerontologia y como diseño del estudio, las entrevistas semiestructuradas tuvieron un mayor número de publicaciones. Consideraciones finales: El género femenino, el grado de dependencia funcional y la estrecha relación con el agresor representan atributos importantes asociados con las víctimas de abuso. Miembros masculinos, solteros y familiares caracterizan el perfil del agresor. La información sobre los factores de riesgo asociados con la violencia contra las personas mayores ayuda a definir el problema y tratarlo.

Palabra clave: Anciano, Factores de riesgo, Violencia.

${ }^{1}$ Pontifícia da Universidade Católica de Minas Gerais (PUC Minas), Belo Horizonte - MG.

*E-mail: joaonsnovaesjr@gmail.com

SUBMETIDO EM: $8 / 2020$

ACEITO EM: 9/2020

PUBLICADO EM: 11/2020

REAS/EJCH | Vol.12(11) | e4915 | DOI: https://doi.org/10.25248/reas.e4915.2020 Página 1 de 10 


\section{INTRODUÇÃO}

O envelhecimento da população é uma realidade mundial. Estima-se que, até 2050, uma em cada 5 pessoas terá 60 anos ou mais (WHO, 2019). O cenário brasileiro não é diferente, segundo estimativas do Instituto Brasileiro de Geografia e Estatística (IBGE), em 2031, o Brasil poderá ter seu número de jovens (0 14 anos) ultrapassado pelo número de idosos (60 anos ou mais). Este fenômeno ocorreu inicialmente em países desenvolvidos e recentemente vem crescendo de forma acentuada nos países em desenvolvimento.

Com efeito, tem-se que a sociedade a qual deveria acolher essa população envelhecida com respeito, com amor e cuidados especiais, principalmente, devido a fragilidade que essas pessoas idosas apresentam, os tratam com total desrespeito, tanto físico, quanto moral, produzindo um ambiente hostil e com maus-tratos (GARBIN CAS, et al., 2016).

A violência contra o idoso pode ser definida como um ato único ou repetitivo que causa dano, lesão ou sofrimento a pessoa idosa ou a falta de medidas apropriadas para evitá-lo, podendo assumir diversas formas como abuso físico, psicológico, emocional ou sexual e abuso de confiança em questões financeiras ou ainda pode ser resultado de negligência, intencional ou não (WHO, 2017).

O problema, embora existente nos países em desenvolvimento e desenvolvidos, geralmente não tem sua epidemiologia definida, pois não é suficientemente relatado em todo o mundo. Apenas em alguns países desenvolvidos existem taxas ou estimativas de prevalência, variando de $1 \%$ a $10 \%$. Nesse contexto, a incidência da violência, tanto em nível nacional quanto mundial, e seu impacto na vida das pessoas e coletividades fizeram com que esta questão se transformasse numa prioridade da saúde pública, pois pela sua complexidade envolve a conscientização e a participação efetiva de toda a sociedade (BRASIL, 2020).

De acordo com Poltronieri BC, et al. (2019), a violência contra o idoso é um problema de saúde pública e pode acarretar sérios danos às vítimas, como aumento da morbimortalidade, institucionalização e admissão hospitalar. Além disso, as consequências da violência são observadas na esfera psicossocial do idoso, podendo afetar sua saúde mental, sua relação familiar e sua vida social.

Ressalta-se que os fatores de risco associados a violência aos idosos, perpassam pela forma de definir, constatar e, sobretudo, resolver o abuso por eles sofrido. Estudos revelam que os casos de violência ocorrem em sua maioria no ambiente familiar, inclusive praticados por pessoas próximas à vítima (LINO VTS, et al., 2019).

Em relação aos abusos sofridos pelos idosos os mais comuns são os físicos, psicológicos, sexuais e financeiros. Além desses abusos, outra forma de violência sofrida por esse público é a negligência em seu tratamento, que mesmo sendo frequente sua constatação é mais complexa (PILLEMER K, et al., 2016).

Normalmente, o abuso cometido aos idosos ocorre de maneira velada, não sendo possível a distinção entre o desgaste do convívio cotidiano e os maus-tratos. Soma-se a isso a perda progressiva de autonomia do idoso, que aliada ao aumento de dependência, favorece aos seus familiares adoção de tratamento permeado de violência física, psicológica e financeira, estabelecendo dessa maneira um padrão de relacionamento abusivo (LINO VTS, et al., 2019).

As práticas abusivas sofridas pelo idoso estão intimamente associadas às características da pessoa que pratica a violência. Com isso, normalmente, o agressor é aquele que apresenta fatores predisponentes como, transtornos psiquiátricos, dependência química, histórico de abandono, abuso físico ou sexual na infância (LINO VTS, et al., 2019).

Diante dos relatos mencionados, é de suma importância compreender os estudos científicos concernentes a violência praticada contra os idosos, já que tal conhecimento pode colaborar no desenvolvimento de estratégias preventivas e proporcionar conscientização, favorecendo a redução de tratamentos abusivos contra a pessoa idosa, sobretudo a mulher, uma vez que as pesquisas apontam que elas são as principais vítimas.

Assim, o presente estudo tem como objetivo identificar os fatores de risco relacionados à violência contra o idoso de modo a nortear estratégias voltadas para o cuidado integral à pessoa idosa e para a prevenção desse agravo. 


\section{MÉTODOS}

Trata-se de uma revisão sistemática, que busca conhecer os fatores de risco que se associam à violência contra o idoso para assim, orientar políticas públicas de cuidado e prevenção desse problema de saúde pública.

Após a definição do objetivo do trabalho, foi necessário definir os critérios de busca da pesquisa. Essas buscas foram realizadas no mês de junho de 2020 nas bases de dados Scientific Electronic Library Online (Scielo) e Portal de Periódicos CAPES. Para isso, utilizamos os Descritores em Ciência e Saúde (DeCS) "idoso" e "violência", os quais foram combinados pelo uso do operador Booleano AND. Os critérios de inclusão utilizados foram os artigos publicados nos últimos 5 anos nos idiomas português, inglês e espanhol. Já os critérios de exclusão foram artigos repetidos e os estudos cuja temática não contemplam o objetivo definido (Figura 1).

A partir da utilização dos critérios estabelecidos, as buscas nas bases de dados tiveram como resultado um total de 295 artigos. Desse total, 84 artigos foram selecionados para a leitura dos títulos e resumos. Após avaliar a adequação à temática proposta 19 artigos foram lidos na íntegra e incluídos neste trabalho.

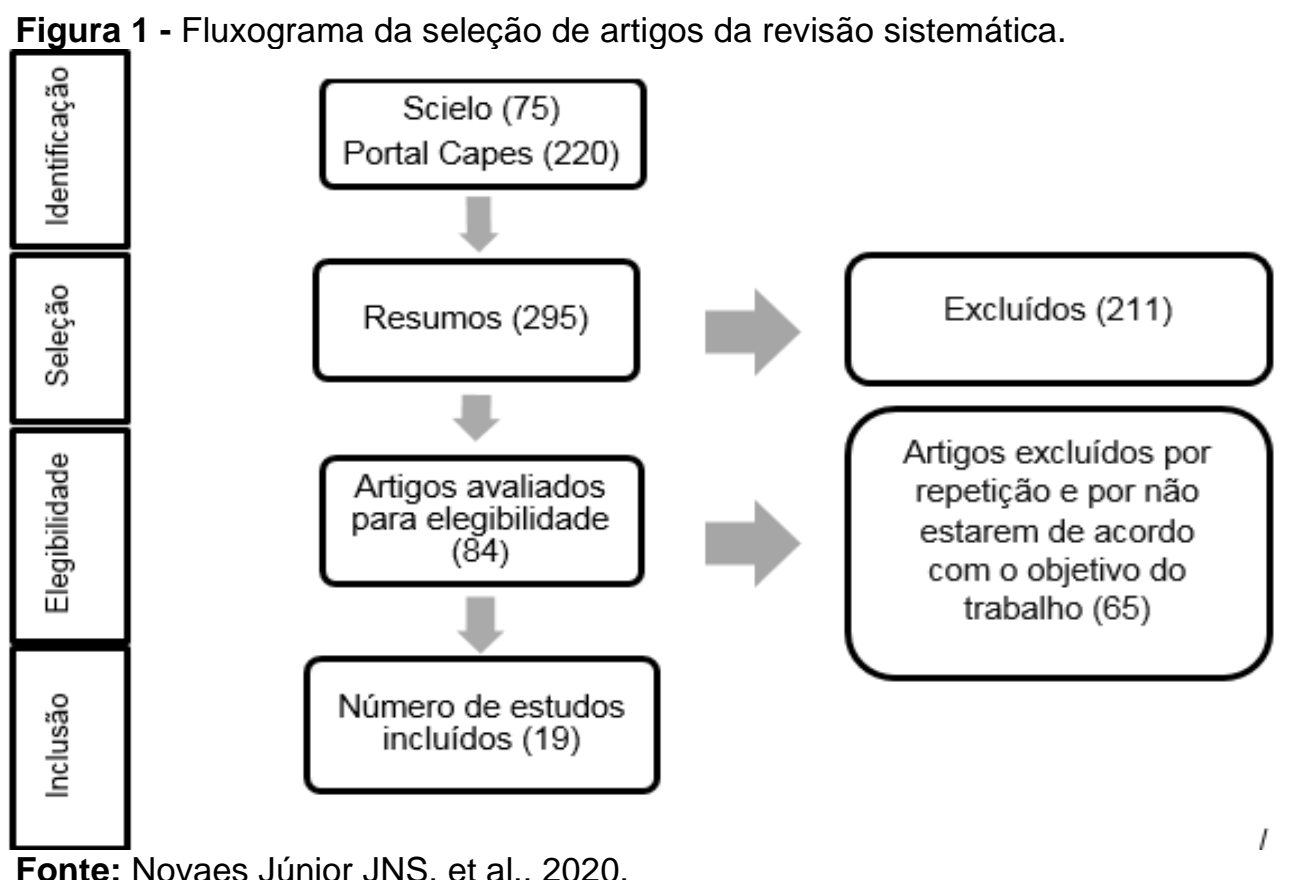

\section{RESULTADOS}

Foram realizadas buscas em 2 plataformas, o CAPES e o SCIELO. Dos 220 artigos encontrados pela combinação dos descritores e filtros no buscador de periódicos CAPES e, após aplicar os critérios de inclusão e exclusão (artigos, revisados aos pares, Brazil e português), restaram 54 artigos. Após a leitura do título e resumo desses 54 artigos, selecionamos 13 artigos para a leitura integral e 3 para a confecção do trabalho.

Além disso, foi feita a busca na base de dados do SCIELO, que dos 75 artigos encontrados com base na associação de descritores e filtros e a partir da leitura dos títulos, foram selecionadas 30 publicações para a leitura integral, utilizando 16 para a realização do trabalho. Os artigos repetidos foram desconsiderados (Quadro 1).

Com relação às bases de dados, utilizou-se o SCIELO e o CAPES, dos anos de 2015 a 2020. Quando se trata do idioma, 17 artigos estavam escritos em português, 1 em espanhol e 1 em inglês, além disso, 18 são produções nacionais. Houve uma prevalência relativa de algumas revistas, como: Revista Brasileira de Enfermagem (4) e Revista Brasileira de Geriatria e Gerontologia (4), Ciência \& Saúde Coletiva (3). Já com relação a prevalência do delineamento dos estudos, as entrevistas semiestruturadas (7), os artigos de revisão da literatura (4) e os estudos de análise documental (3), foram os que apresentaram um maior número. 
Quadro 1 - Autoria/ano, título, periódico, delineamento de estudo, resultados.

\begin{tabular}{|c|c|c|c|c|}
\hline Autoria/Ano & Título & Periódico & Delineamento & Resultados \\
\hline Lino VTS, et al., 2019 & $\begin{array}{c}\text { Prevalência e fatores } \\
\text { associados ao abuso de } \\
\text { cuidadores contra idosos } \\
\text { dependentes: a face oculta da } \\
\text { violência familiar }\end{array}$ & $\begin{array}{l}\text { Ciência \& Saúde } \\
\text { Coletiva }\end{array}$ & $\begin{array}{l}\text { Estudo transversal com } \\
\qquad 135 \text { duplas }\end{array}$ & $\begin{array}{c}\text { A elevada prevalência de maus-tratos por parte de } \\
\text { cuidadores que apresentam altos níveis de } \\
\text { sobrecarga, problemas relacionados ao álcool e que } \\
\text { cuidam de idosos deprimidos requer a adoção de } \\
\text { medidas de apoio familiar. }\end{array}$ \\
\hline Silva CFS e Dias CMSB, 2016 & $\begin{array}{l}\text { Violência Contra Idosos na } \\
\text { Família: Motivações, } \\
\text { Sentimentos e Necessidades } \\
\text { do Agressor }\end{array}$ & $\begin{array}{l}\text { Psicologia: } \\
\text { Ciência e } \\
\text { Profissão }\end{array}$ & $\begin{array}{l}\text { Pesquisa descritiva de } \\
\text { abordagem qualitativa com } \\
13 \text { agressores familiares, } \\
\text { por meio de entrevistas } \\
\text { semiestruturada. }\end{array}$ & $\begin{array}{c}\text { Presença de violência com agressões verbais e } \\
\text { físicas; as principais motivações foram uso de álcool, } \\
\text { proximidade física, dependência financeira do } \\
\text { agressor em relação ao idoso e relacionamento } \\
\text { permeado de violência entre ambos. }\end{array}$ \\
\hline Lopes EDS, et al., 2018 & $\begin{array}{l}\text { Maus-tratos a idosos no Brasil: } \\
\text { uma revisão integrativa }\end{array}$ & $\begin{array}{l}\text { Revista } \\
\text { Brasileira de } \\
\text { Geriatria e } \\
\text { Gerontologia }\end{array}$ & $\begin{array}{l}\text { Revisão integrativa da } \\
\text { literatura, analisando } 28 \\
\text { artigos de } 2013 \text { a } 2017\end{array}$ & $\begin{array}{l}\text { Evidenciou que as principais violências sofridas } \\
\text { foram à psicológica juntamente com a física, sendo } \\
\text { as idosas as principais vítimas. O principal local de } \\
\text { ocorrência de maus-tratos foi na própria residência. }\end{array}$ \\
\hline Rodrigues RAP, et al., 2017 & $\begin{array}{l}\text { Violência contra idosos em três } \\
\text { municípios brasileiros }\end{array}$ & $\begin{array}{l}\text { Revista } \\
\text { Brasileira de } \\
\text { Enfermagem }\end{array}$ & $\begin{array}{l}\text { Estudo ecológico, } \\
\text { analisando } 2.612 \text { boletins } \\
\text { de ocorrência. }\end{array}$ & $\begin{array}{l}\text { Predominou a violência psicológica, na maioria dos } \\
\text { casos na própria residência do idoso. }\end{array}$ \\
\hline Garbin CAS, et al., 2016 & $\begin{array}{l}\text { Idosos vítimas de maus-tratos: } \\
\text { cinco anos de análise } \\
\text { documental }\end{array}$ & $\begin{array}{l}\text { Revista } \\
\text { Brasileira de } \\
\text { Geriatria e } \\
\text { Gerontologia }\end{array}$ & $\begin{array}{l}\text { Estudo transversal, } \\
\text { descritivo e retrospectivo } \\
\text { de análise documental } \\
\text { (ocorrências policiais). }\end{array}$ & $\begin{array}{c}\text { As mulheres da raça branca, casadas com idade } \\
\text { entre } 60-65 \text {, aposentadas são as principais vítimas, e } \\
\text { os agressores são os próprios filhos, com idade entre } \\
31-40 \text { anos. A violência psicológica foi a mais } \\
\text { prevalente, desencadeada desentendimento entre os } \\
\text { envolvidos e na própria residência da vítima. }\end{array}$ \\
\hline Santos MABS, et al., 2020 & $\begin{array}{l}\text { Fatores associados à violência } \\
\text { contra o idoso: uma revisão } \\
\text { sistemática da literatura }\end{array}$ & $\begin{array}{l}\text { Ciência \& Saúde } \\
\text { Coletiva }\end{array}$ & $\begin{array}{l}\text { Revisão sistemática da } \\
\text { literatura de estudos } \\
\text { epidemiológicos analíticos. } \\
\text { Selecionando } 27 \text { artigos. }\end{array}$ & $\begin{array}{l}\text { Os fatores associados à violência geral foram idade, } \\
\text { sexo, estado civil, nível de educação, renda, arranjo } \\
\text { familiar, suporte social, solidão, transtorno mental, } \\
\text { depressão, tentativa de suicídio, dependência para } \\
\text { atividades da vida diária, função cognitiva, abuso de } \\
\text { álcool ou drogas, entre outros. }\end{array}$ \\
\hline Santana IO, et al., 2016 & $\begin{array}{c}\text { Prevalência da violência contra } \\
\text { o idoso no Brasil: revisão } \\
\text { analítica }\end{array}$ & $\begin{array}{l}\text { Arquivos } \\
\text { Brasileiros de } \\
\text { Psicologia }\end{array}$ & $\begin{array}{l}\text { Analítica revisão } \\
\text { sistemática da literatura. } \\
\text { Analisando } 6 \text { artigos }\end{array}$ & $\begin{array}{c}\text { Os tipos de violência prevalentes foram: violência } \\
\text { psicológica, violência física e roubo. Sendo os } \\
\text { membros das famílias os principais responsáveis por } \\
\text { esse tipo de violência. }\end{array}$ \\
\hline
\end{tabular}

REAS/EJCH | Vol.12(11) | e4915 | DOI: https://doi.org/10.25248/reas.e4915.2020 Página 4 de 10 
Revista Eletrônica Acervo Saúde / Electronic Journal Collection Health | ISSN 2178-2091

\begin{tabular}{|c|c|c|c|c|}
\hline Autoria/Ano & Título & Periódico & Delineamento & Resultados \\
\hline Barros RCM, et al., 2019 & $\begin{array}{l}\text { Violência doméstica contra } \\
\text { idosos assistidos na atenção } \\
\text { básica. }\end{array}$ & $\begin{array}{l}\text { Saúde em } \\
\text { Debate }\end{array}$ & $\begin{array}{l}\text { Estudo descritivo de corte } \\
\text { transversal, por meio de } \\
\text { entrevistas com } 169 \\
\text { indivíduos de } 60 \text { anos ou } \\
\text { mais. }\end{array}$ & $\begin{array}{l}\text { Prevalência de } 78,7 \% \text { dos idosos com sinais } \\
\text { indicativos de pelo menos um tipo de violência em } \\
\text { seu ambiente doméstico, sendo a negligência o tipo } \\
\text { mais prevalente, seguida de violência psicológica e } \\
\text { financeira. }\end{array}$ \\
\hline Maia PHS, et al., 2019 & $\begin{array}{l}\text { A ocorrência da violência em } \\
\text { idosos e seus fatores } \\
\text { associados }\end{array}$ & $\begin{array}{l}\text { Revista } \\
\text { Brasileira de } \\
\text { Enfermagem }\end{array}$ & $\begin{array}{l}\text { Estudo transversal } \\
\text { realizado através de } \\
\text { entrevistas estruturadas } \\
\text { com } 178 \text { idosos. }\end{array}$ & $\begin{array}{l}\text { As formas mais prevalentes de violência foram a falta } \\
\text { de acesso a direitos sociais, a violência verbal, } \\
\text { moral/psicológica, falta de cuidados, violência física, } \\
\text { sexual e discriminação. As mulheres sofreram mais } \\
\text { abusos que os homens e houve maior associação } \\
\text { com o grau de sintomas depressivos. }\end{array}$ \\
\hline Silva ES, et al., 2019 & $\begin{array}{l}\text { Elementos da formação do } \\
\text { enfermeiro na prevenção da } \\
\text { violência contra a pessoa idosa }\end{array}$ & $\begin{array}{c}\text { Ciencia y } \\
\text { Enfermeria }\end{array}$ & $\begin{array}{l}\text { Pesquisa de abordagem } \\
\text { qualitativa por meio de um } \\
\text { roteiro de entrevista } \\
\text { semiestruturado com } 24 \\
\text { enfermeiros }\end{array}$ & $\begin{array}{l}\text { A educação permanente de profissionais para que } \\
\text { estejam preparados para intervenções em casos de } \\
\text { violência, possibilita a oportunidade de detectar } \\
\text { situações de violência e realizar intervenções. }\end{array}$ \\
\hline Poltronieri BC, et al., 2019b & $\begin{array}{l}\text { Violência no cuidado em } \\
\text { instituições de longa } \\
\text { permanência para idosos no } \\
\text { Rio de Janeiro: percepções de } \\
\text { gestores e profissionais }\end{array}$ & $\begin{array}{l}\text { Saúde e } \\
\text { Sociedade }\end{array}$ & $\begin{array}{c}\text { Estudo qualitativo com } 38 \\
\text { entrevistas } \\
\text { semiestruturadas }\end{array}$ & $\begin{array}{c}\text { A violência se manifesta de várias formas, como a } \\
\text { negligência e abandono na pré-institucionalização e, } \\
\text { no interior das ILPI, por preconceitos, na visão } \\
\text { negativa da velhice, na infantilização e } \\
\text { despersonalização. Além disso, no contexto } \\
\text { macropolítico pela ausência ou não do cumprimento } \\
\text { das políticas públicas ou na falta de legislações. }\end{array}$ \\
\hline Poltronieri BC, et al., 2019a & $\begin{array}{l}\text { Análise do tema violência nas } \\
\text { políticas de cuidado de longa } \\
\text { duração ao idoso }\end{array}$ & $\begin{array}{c}\text { Ciência \& Saúde } \\
\text { Coletiva }\end{array}$ & $\begin{array}{c}\text { Revisão integrativa } \\
\text { analisando um total de } 77 \\
\text { artigos }\end{array}$ & $\begin{array}{c}\text { O que fica em evidência nas ILPI com relação à } \\
\text { violência são a negligência e o abandono. Fato que } \\
\text { ocorre mais em países da América Latina e Ásia. }\end{array}$ \\
\hline Oliveira KSM, et al., 2018 & $\begin{array}{l}\text { Violência contra idosos: } \\
\text { concepções dos profissionais } \\
\text { de enfermagem acerca da } \\
\text { detecção e prevenção }\end{array}$ & $\begin{array}{l}\text { Revista Gaúcha } \\
\text { de Enfermagem }\end{array}$ & $\begin{array}{l}\text { Estudo descritivo, } \\
\text { exploratório, qualitativo, } \\
\text { utilizando roteiro de } \\
\text { entrevista semiestruturada } \\
\text { com } 4 \text { enfermeiros e } 6 \\
\text { técnicos de enfermagem. }\end{array}$ & $\begin{array}{l}\text { Muitos profissionais reconhecem/desconfiam dos } \\
\text { possíveis casos, entretanto, não sabem como } \\
\text { proceder. A dimensão do problema exige que sejam } \\
\text { realizadas intervenções pragmáticas no meio clínico } \\
\text { e no contexto social. }\end{array}$ \\
\hline Castro VC, et al., 2018 & $\begin{array}{l}\text { Violência contra os idosos } \\
\text { brasileiros: uma análise das } \\
\text { internações hospitalares }\end{array}$ & $\begin{array}{c}\text { Revista } \\
\text { Brasileira de } \\
\text { Enfermagem }\end{array}$ & $\begin{array}{l}\text { Pesquisa quantitativa, } \\
\text { descritiva, transversal com } \\
\text { idosos internados por } \\
\text { agressões. Obtidas nas } \\
\text { bases de dados do } \\
\text { DATASUS. }\end{array}$ & $\begin{array}{c}\text { A prevalência das internações por agressão corporal } \\
\text { prevaleceu em idosos entre } 60 \text { e } 69 \text { anos, homens, } \\
\text { no setor público. Para negligência e abandono, } \\
\text { verificou-se prevalência maior em mulheres, com } \\
\text { mais de } 80 \text { anos, no setor público }\end{array}$ \\
\hline
\end{tabular}

REAS/EJCH | Vol.12(11) | e4915 | DOI: https://doi.org/10.25248/reas.e4915.2020 Página 5 de 10 
Revista Eletrônica Acervo Saúde / Electronic Journal Collection Health | ISSN 2178-2091

\begin{tabular}{|c|c|c|c|c|}
\hline Autoria/Ano & Título & Periódico & Delineamento & Resultados \\
\hline Irigaray TQ, et al., 2016 & $\begin{array}{l}\text { Maus-tratos contra idosos em } \\
\text { Porto Alegre, Rio Grande do } \\
\text { Sul: um estudo documental }\end{array}$ & $\begin{array}{l}\text { Estudos de } \\
\text { Psicologia } \\
\text { (Campinas) }\end{array}$ & $\begin{array}{l}\text { Um estudo documental e } \\
\text { retrospectivo com base em } \\
224 \text { boletins de ocorrência } \\
\text { da Delegacia de Proteção } \\
\text { ao Idoso }\end{array}$ & $\begin{array}{c}\text { Os maus-tratos psicológicos foram os mais } \\
\text { frequentes, seguidos pelo abuso financeiro ou } \\
\text { material. A vítima, na maioria dos casos, foi do sexo } \\
\text { feminino e de baixa escolaridade. O agressor, } \\
\text { geralmente, era do sexo masculino e familiar da } \\
\text { vítima. }\end{array}$ \\
\hline Paraíba PMF e Silva MCM, 2015 & $\begin{array}{l}\text { Perfil da violência contra a } \\
\text { pessoa idosa na cidade do } \\
\text { Recife-PE }\end{array}$ & $\begin{array}{l}\text { Revista } \\
\text { Brasileira de } \\
\text { Geriatria e } \\
\text { Gerontologia }\end{array}$ & $\begin{array}{l}\text { Estudo descritivo de corte } \\
\text { transversal, por meio de } \\
\text { dados obtidos de } 242 \\
\text { Fichas de notificação do } \\
\text { sistema VIVA }\end{array}$ & $\begin{array}{l}\text { Maior parte das vítimas era do sexo feminino, tendo } \\
\text { como agressor o filho, do sexo masculino. A violência } \\
\text { física foi a forma de agressão mais observada, } \\
\text { ocorrida, em maior parte, nas residências. }\end{array}$ \\
\hline Bolsoni CC, et al., 2016 & $\begin{array}{l}\text { Prevalência de violência contra } \\
\text { idosos e fatores associados, } \\
\text { estudo de base populacional } \\
\text { em Florianópolis, SC }\end{array}$ & $\begin{array}{l}\text { Revista } \\
\text { Brasileira de } \\
\text { Geriatria e } \\
\text { Gerontologia }\end{array}$ & $\begin{array}{l}\text { Estudo de base } \\
\text { populacional, conduzido } \\
\text { com } 1.705 \text { indivíduos com } \\
60 \text { anos ou mais, por meio } \\
\text { do questionário SABE }\end{array}$ & $\begin{array}{c}\text { A prevalência de violência foi aproximadamente } 13 \% \text {, } \\
\text { e a verbal ocorreu com } 11,0 \% \text {. Ser do sexo feminino } \\
\text { e idoso (a) solteiro (a) ou divorciado (a) tiveram } \\
\text { chance } 66 \% \text { maior de sofrer violência. Aqueles que } \\
\text { moram com filhos ou netos apresentam chance duas } \\
\text { vezes maior. }\end{array}$ \\
\hline Paiva MM e Tavares DMS, 2015 & $\begin{array}{l}\text { Violência física e psicológica } \\
\text { contra idosos: prevalência e } \\
\text { fatores associados }\end{array}$ & $\begin{array}{c}\text { Revista } \\
\text { Brasileira de } \\
\text { Enfermagem }\end{array}$ & $\begin{array}{l}\text { Inquérito domiciliar por } \\
\text { meio de entrevista, } \\
\text { conduzido com } 729 \text { idosos }\end{array}$ & $\begin{array}{l}\text { A prevalência de idosos sob violência foi de } 20,9 \% \text {, } \\
\text { sendo } 5,9 \% \text { para física e } 20,9 \% \text { para psicológica. } \\
\text { Entre eles, prevaleceram mulheres, com idade entre } \\
60 \text { - } 80 \text { anos, sem escolaridade, com renda, tendo } \\
\text { como principal agressor o cônjuge; com auto } \\
\text { percepção negativa de saúde; hospitalização no } \\
\text { último ano; e presença de multimorbidades. }\end{array}$ \\
\hline Pillemer K, et al., 2016 & $\begin{array}{c}\text { Elder Abuse: Global Situation, } \\
\text { Risk Factors, and Prevention } \\
\text { Strategies }\end{array}$ & $\begin{array}{l}\text { The } \\
\text { Gerontological } \\
\text { Society of } \\
\text { America }\end{array}$ & $\begin{array}{l}\text { Revisão de escopo dos } \\
\text { principais problemas da } \\
\text { área, de uma perspectiva } \\
\text { internacional. }\end{array}$ & $\begin{array}{l}\text { Os resultados destacam um crescente consenso } \\
\text { entre os estudos sobre a extensão e as causas dos } \\
\text { maus-tratos a idosos, bem como a necessidade } \\
\text { urgente de esforços para tornar os programas de } \\
\text { prevenção de maus-tratos a idosos mais eficazes e } \\
\text { baseados em evidências. }\end{array}$ \\
\hline
\end{tabular}

Fonte: Novaes Júnior JNS, et al., 2020.

REAS/EJCH | Vol.12(11) | e4915 | DOI: https://doi.org/10.25248/reas.e4915.2020 Página 6 de 10 


\section{DISCUSSÃO}

O abuso contra o idoso se manifesta de diferentes formas. Segundo Lopes EDS, et al. (2018), os principais tipos de violência praticadas contra o idoso são a psicológica e a física, seguida do abuso financeiro. No Brasil, entretanto, não há consenso estabelecido sobre a prevalência nacional referente às formas de abusos. As variações nas estimativas de violência contra o idoso encontradas na literatura brasileira podem estar relacionadas aos métodos de pesquisa utilizados, local do estudo e representatividade das amostras coletadas (IRIGARAY TQ, et al., 2016).

Um estudo publicado por Silva CFS e Dias CMSB (2016) destaca a negligência, seguida da violência psicológica e financeira como os tipos mais prevalentes. De forma semelhante, a negligência representou o tipo de violência mais prevalente sofrida por idosos em ambiente doméstico, seguida pelos abusos psicológicos e financeiros (BARROS RCM, et al., 2019).

Diversos fatores contribuem para a ocorrência de abusos contra a pessoa idosa, bem como para seus desfechos. Dados da literatura apontam que, características da vítima como idade, sexo, estado civil, nível educacional, renda, arranjo familiar e grau de dependência, podem estar associados ao maior risco de violência. De fato, estudos demonstram a prevalência de maus-tratos em idosas, solteiras, com idade avançada, baixo nível de escolaridade e/ou portadoras de alguma dependência física ou psicológica (CASTRO VC, et al., 2018).

Segundo Bolsoni CC, et al. (2016), a mulher idosa apresenta chance duas vezes superior de sofrer violência em relação ao homem idoso. O estudo ainda aponta que idosos solteiros ou divorciados apresentaram chance $66 \%$ maior de sofrer abuso. Irigaray TQ, et al. (2016) analisaram dados dos boletins de ocorrência registrados na Delegacia de Proteção ao Idoso, município de Porto Alegre/RS, com o intuito de identificar aspectos relacionados à maus-tratos sofridos por idosos.

A maior parte das vítimas de abusos era do sexo feminino, com média etária de 70 anos, sem cônjuge (viúva, solteira ou separada) e com baixa escolaridade. Barros RCM, et al. (2019) e Paraíba PMF e Silva MCM (2015) encontraram perfil similar em estudos conduzido na cidade de Recife/PE.

Ademais, um estudo realizado na cidade de Uberaba/MG, a fim de traçar o perfil sociodemográfico do idoso vítima de violência física e psicológica demostrou que há uma maior prevalência de vítimas do sexo feminino, de faixa etária entre 60 e 80 anos, sem escolaridade e detentoras de renda. Esse estudo ainda apontou a vivência com o cônjuge e a dependência para atividades instrumentais de vida diária como elementos associados à vítima de violência (PAIVA MM e TAVARES DMS, 2015).

A alta prevalência de vítimas pertencentes ao sexo feminino denota a influência da violência de gênero em nossa sociedade, presente em diversos ambientes e faixas etárias e agravada pelo envelhecimento. Esse fato alarmante decorre da estreita relação entre violência de gênero e violência doméstica, ambos, frequentemente, observados em situações de abuso contra idosas. Em relação às agressões cometidas contra os idosos, a violência contra a mulher possui uma prevalência, em média $64 \%$ dos casos denunciados.

Essa violência, ainda pouco explorada e estudada, mas muito comum, é destacada pela sua tipologia, como a psicológica que representa $28 \%$ dos casos, a física $28 \%$ e financeira $12 \%$ (LOPES EDS, 2018). Aliado a isso, Santana IO, et al. (2016) pontuam que mulheres idosas tendem a sofrer maiores consequências no que se refere aos maus-tratos, principalmente, aquelas que apresentam transtornos depressivos.

A associação entre sintomas depressivos e violência contra a mulher idosa é corroborada em outros estudos. Idosas vítimas de violência apresentaram alto grau de sintomas depressivos. O estado de fragilidade mental criado por situações de violência pode gerar outras consequências igualmente graves como a cronificação de comorbidades, isolamento social e perda de capacidade funcional (MAIA PHS, et al., 2019).

A dependência funcional, perda da capacidade cognitiva e comprometimento da saúde mental dos idosos representam fatores de risco para a ocorrência de abusos (PILLEMER K, et al., 2016). De acordo com Oliveira KSM, et al. (2018), a dependência física ou mental associada à maior demanda por cuidados torna o idoso mais vulnerável à violência. 
Consonante com essa afirmativa, um estudo publicado por Bolsoni CC, et al. (2016) realizado em Florianópolis/SC, demonstra que idosos com dependência de moderada à grave apresentaram uma chance $70 \%$ maior de sofrer algum tipo de violência. Somado a isso, o aumento da demanda por cuidados, convívio familiar estressante e o despreparo dos cuidadores podem agravar esta situação (BOLSONI CC, et al., 2016).

Conforme Rodrigues RAP (2017) a família é a principal rede de apoio e cuidado dos idosos, porém em grande parte dos casos são os próprios familiares que cometem tais atos de violência contra o idoso. Esses familiares, normalmente, os filhos como já exposto, apresentam perfis semelhantes e são em sua maioria do sexo masculino, faixa etária entre 30 e 49 anos, não moram com o idoso (RODRIGUES RAP, 2017). Garbin CAS, et al. (2016) também verificou perfil similar do agressor, o qual é composto por homens, brancos, solteiros e idade entre 31 e 40 anos.

Outros estudos apontam que a maior parte dos casos de violência ocorreu em ambiente doméstico e foi perpetrada, principalmente, pelos filhos das vítimas, as quais eram mulheres na maioria dos casos. Segundo estimativas de Bolsoni CC, et al. (2016), idosos que moram com os filhos ou netos apresentam chance duas vezes maior de sofrer violência, confirmando o caráter de proximidade entre vítima e agressor.

Além da presença de laços de parentesco com a vítima, Silva CFS e Dias CMSB (2016), apontam outras características do agressor que podem representar risco para a ocorrência de maus-tratos, dentre as quais destaca-se o uso de álcool ou drogas, dependência financeira do agressor em relação à vítima e histórico de violência intrafamiliar.

Além da dependência da família, a necessidade de divisão de espaço com os idosos, o despreparo dos filhos para cuidado e a falta de paciência com as vítimas, contribuem para um ambiente propenso para abusos. Por isso, uma maior atenção aos familiares com a promoção da educação sobre cuidados com os idosos seria um fator positivo para diminuição desse tipo de crime (RODRIGUES RAP, 2017; SILVA CFS e DIAS CMSB, 2016).

Um dos grandes empecilhos no combate da violência contra o idoso é a subnotificação dos casos. $O$ cenário parece piorar nas situações em que o abuso ocorre no ambiente doméstico. Fatores como: vínculo afetivo com o cuidador, medo de institucionalização, constrangimento, culpa, baixa autoestima e receio de represália por parte do agressor podem comprometer as denúncias de maus-tratos (GARBIN CAS, et al., 2016). Dessa forma, torna-se essencial a existência de políticas voltadas para a proteção e cuidado integral ao idoso.

No Brasil, as principais políticas públicas voltadas ao idoso são: a Política Nacional do Idoso (Lei nำ 8.842 , de 4 de janeiro de 1994), o Estatuto do Idoso (Lei oㅜ 10.741, de 1ํ de outubro de 2003) e a Política Nacional de Saúde da Pessoa Idosa (Portaria no 2.528, de 19 de outubro de 2006).

A Política Nacional do Idoso (PNI) promulgada pela lei ํo 8.842 de 4 de janeiro de 1994, regulamentada pelo Decreto o 1948 em 03 de junho de 1996, tem como objetivo assegurar direitos sociais aos idosos, bem como criar condições que promovam a autonomia, integração social, participação efetiva na sociedade e a reafirmação do direito à saúde dentro dos diversos níveis de atendimento do Sistema Único de Saúde (SUS) (BRASIL, 1994).

Outro documento importante é o Estatuto do Idoso que através da lei no 10.741 , de 1ํ de outubro e aprovado em 2003, assegura os direitos humanos resguardados à população idosa no Brasil. Esse estatuto trata-se de uma conquista da pessoa idosa acerca de seus direitos, principalmente, por buscar nas esferas da família, sociedade e Estado formas de proteção que assegurem o respeito, bem como promoção da qualidade de vida dessa público alvo (BRASIL, 2003).

Já a Política Nacional de Saúde da Pessoa Idosa (PNSPI), instituída pela portaria 2528/GM de 19 de outubro de 2006, busca garantir a atenção adequada e digna para a população idosa brasileira, visando sua integração (BRASIL, 2006).

Apesar das políticas públicas existentes ainda são necessários outros passos para o idoso tenha os seus direitos assegurados. No que diz respeito, a atuação dos profissionais de saúde, no cenário de violência contra o idoso, é fundamental que o profissional esteja capacitado para detectar e atuar nesse contexto. 
Diante desse cenário, dentro da percepção de gestores de Instituições de Longa Permanência (ILPI), uma pesquisa foi realizada com 29 gestores entrevistados e suas formações variavam entre ensino médio, técnico e superior, como enfermeiros, psicólogos, assistente social, nutricionista, fisioterapeuta, fonoaudiólogo e pedagogo.

Nesse estudo, houve um recorte sobre a violência dentro das ILPI e, de acordo com a percepção dos gestores e profissionais da saúde que atuavam nos locais, a negligência e o abandono por parte dos familiares e também no ambiente doméstico, na vivência desses idosos, já acontecia antes mesmo da institucionalização. Outro ponto apontado pelo estudo foi em relação a ausência de políticas públicas de fato efetivas e resolutivas para o cuidado a pessoa idosa no Brasil (POLTRONIERI BC, et al., 2019b).

Dentro desse contexto, uma pesquisa feita em uma cidade do interior do Maranhão, mostra que na formação de enfermeiros, por exemplo, há pouca ou nenhuma discussão acerca do tema. Assim como, esse estudo aponta que não é habitual que os profissionais tenham treinamento para atuarem na prevenção com ações da Estratégia de Saúde da Família voltadas a pessoa idoso, o que demonstra a dificuldade em detectar sinais de agressões ou abusos (SILVA ES, et al., 2019).

Por essas razões apresentadas considera-se, extremamente importante que o profissional de saúde saiba como atuar nas situações de violência contra o idoso, uma vez que, após a reformulação do artigo 19 da lei n. 10.741 dentro do Estatuto do Idoso, torna-se obrigatória e de caráter compulsório a notificação dos casos de violência suspeita ou confirmada contra a pessoa idosa.

Dessa forma, através das notificações, é possível dar visibilidade para o problema, bem como promover o levantamento epidemiológico que dê amparo a criação de políticas públicas que visem a prevenção das agressões (BRASIL, 2003).

Por fim, é demonstrado na literatura que até mesmo os profissionais se deparam com a ausência de uma referência ou rede de apoio que ofereça soluções para o problema de forma multidisciplinar. A ausência de produções científicas a cerca desta temática são um desafio para acadêmicos e profissionais da área da saúde. Debater esse tema, é importante para que se aprimorem resoluções para enfrentamento da violência contra o idoso com ações que unam a sociedade e o Estado, principalmente na Atenção Primária à Saúde.

Para isso, é necessário utilizar estratégias coletivas que atuem na prevenção das agressões e violências, promovendo ações em saúde aos idosos, bem como a abordagem aos familiares em busca da redução desse problema, por meio de práticas de Educação em Saúde (OLIVEIRA KSM, et al., 2018).

\section{CONSIDERAÇÕES FINAIS}

A violência contra o idoso é um fenômeno complexo e multifatorial. As informações presentes neste estudo apontam o gênero feminino, o grau de dependência funcional e a relação de proximidade com agressor como importantes atributos associados às vítimas de abusos. Indivíduos do sexo masculino, solteiros e membro da própria família caracterizam o perfil do agressor. Embora o Brasil disponha de mecanismos legais para a proteção do idoso, a elevada subnotificação dos casos de abuso faz parte da realidade do país, ocultando a extensão do problema e limitando as ações de combate a esse agravo. A identificação de fatores que favorecem a prática de violência contra a pessoa idosa, bem como a caracterização do perfil do agressor podem auxiliar na elaboração de estratégias de prevenção e promoção do cuidado integral à vítima de violência, contribuindo no enfrentamento desse problema de saúde pública.

\section{REFERÊNCIAS}

1. BARROS RLM, et al. Violência doméstica contra idosos assistidos na atenção básica. Saúde em Debate, 2019; 43(122): 2358-2898.

2. BOLSONI CC, et al. Prevalência de violência contra idosos e fatores associados, estudo de base populacional em Florianópolis, SC. Revista Brasileira de Geriatria e Gerontologia, 2016; 19(4): 671-682.

3. BRASIL. Lei n. 10.741, de 1ํ de outubro de 2003. Dispõe sobre o Estatuto do Idoso e dá outras providências. Brasília: 2003. Disponível em: http://www.planalto.gov.br/ccivil_03/leis/2003/l10.741.htm. Acesso em: 12 jun. 2020 
4. BRASIL. Lei n. 8.842, de 04 de janeiro de 1994. Dispõe sobre a Política Nacional do Idoso, cria o Conselho Nacional do Idoso e dá outras providências. Brasília: 1994. Disponível em: http://www.planalto.gov.br/ccivil_03/leis/L8842.htm. Acesso em: 13 jun. 2020

5. BRASIL. Ministério da Saúde. Portaria № 2.528 De 19 de Outubro de 2006. Aprova a Política Nacional de Saúde da Pessoa Idosa. Brasília: 2006. https://bvsms.saude.gov.br/bvs/saudelegis/gm/2006/prt2528_19_10_2006.html. Acesso em: 10 jun. 2020

6. BRASIL. Ministério da Saúde. Dia Mundial de Conscientização da Violência Contra a Pessoa Idosa. Brasília. 2020. Disponível em: http://bvs.saude.gov.br/component/content/article?id=3209. Acesso em: 14 jun. 2020.

7. CASTRO VC, et al. Violência contra os idosos brasileiros: uma análise das internações hospitalares. Revista Brasileira de Enfermagem, 2018; 71.

8. GARBIN CAS, et al. Idosos vítimas de maus-tratos: cinco anos de análise documental. Revista Brasileira de Geriatria e Gerontologia, 2016; 19(1): 87-94.

9. HOHENDORFF JV, et al., Caracterização da violência contra idosos a partir de casos notificados por profissionais da saúde. Revista da SPAGESP, 2018; 19(2): 64-80.

10. IBGE: Projeção da População (revisão 2018), Rio de Janeiro, 25/07/2018

11. IRIGARAY TQ, et al. Maus-tratos contra idosos em Porto Alegre, Rio Grande do Sul: um estudo documental. Estudos de Psicologia (Campinas), 2016; 33(3): 543-551.

12. LINO VTS, et al. Prevalência e fatores associados ao abuso de cuidadores contra idosos dependentes: a face oculta da violência familiar. Ciência \& Saúde Coletiva, 2019; 24(1): 87-96.

13. LOPES EDS, et al. Elder abuse in Brazil: an integrative review. Rev. bras. geriatr. gerontol, 2018; 21 (5): 628-638.

14. MAIA PHS, et al. A ocorrência da violência em idosos e seus fatores associados. Revista Brasileira de Enfermagem, 2019; 72: 64-70.

15. OLIVEIRA KSM, et al., Violência contra idosos: concepções dos profissionais de enfermagem acerca da detecção e prevenção. Revista Gaúcha de Enfermagem, 2018; 39: 1983-1447.

16. PAIVA MM, TAVARES DMS. Violência física e psicológica contra idosos: prevalência e fatores associados. Revista Brasileira de Enfermagem, 2015; 68(6): 1035-1041.

17. PARAÍBA PMF, SILVA MCM. Perfil da violência contra a pessoa idosa na cidade do Recife-PE. Revista Brasileira de Geriatria e Gerontologia, 2015; 18(2): 295-306.

18. PILLEMER K, et al. Elder abuse: global situation, risk factors, and prevention strategies. The Gerontologist, $2016 ; 56$ (Supl 2): 194-205.

19. POLTRONIERI BC, et al., Análise do tema violência nas políticas de cuidado de longa duração ao idoso. Ciência \& Saúde Coletiva, 2019a; 24(8): 1678-4561

20. POLTRONIERI BC, et el., Violência no cuidado em instituições de longa permanência para idosos no Rio de Janeiro: percepções de gestores e profissionais. Saúde e Sociedade, 2019b; 28(2): 1984-0470

21. RODRIGUES RAP, et al. Violência contra idosos em três municípios brasileiros. Rev. Bras. Enferm. Brasília, 2017; 70(4): 783-791.

22. SANTANA IO, et al. Prevalência da violência contra o idoso no Brasil: revisão analítica. Arquivos Brasileiros de Psicologia, 2016; 68(1): 1809-5267.

23. SANTOS MABS, et al. Fatores associados à violência contra o idoso: uma revisão sistemática da literatura. Ciência \& Saúde Coletiva, 2020; 25(6): 1678-4561.

24. SILVA CFS, DIAS CMSB. Violência contra idosos na família: motivações, sentimentos e necessidades do agressor. Psicologia: Ciência e Profissão, 2016; 36(3): 637-652.

25. SILVA ES, et al., Investigación elementos de la formación del enfermero en la prevención de la violencia contra el adulto mayor. Ciencia y enfermería, 2019; 25(7): 0717-9553.

26. TEIXEIRA EC. O Papel das Políticas Públicas no Desenvolvimento Local e na Transformação da Realidade, 2002; AATR-BA.

27. WORLD HEALTH ORGANIZATION (WHO). Elder abuse. Geneva: WHO; 2017. Disponível em: <https://www.who.int/ageing/projects/elder_abuse/en/>. Acesso em: 10 jun. 2020.

28. WORLD HEALTH ORGANIZATION (WHO). Integrated care for older people (ICOPE): guidance for person-centred assessment and pathways in primary care. Geneva: WHO; 2019.2 Disponível em: https://www.who.int/ageing/publications/icope-handbook/en/. Acesso em: 11 jun. 2020. 